\title{
Race- and Sex-Based Disparities in the Therapy and Outcomes of Squamous Cell Carcinoma of the Anus
}

\author{
Nivedita Arora, MBBS ${ }^{\mathrm{a}}$; Arjun Gupta, MBBS ; Hong Zhu, PhD ${ }^{\mathrm{b}}$; Alana Christie, BS, $\mathrm{MS}^{\mathrm{b}}$; \\ Jeffrey J. Meyer, MDc; Saad A. Khan, MBBS'; and Muhammad S. Beg, MBBS ${ }^{d}$
}

\begin{abstract}
Background: Squamous cell carcinoma of the anus (SCCA) is one of the few cancers with an increasing incidence in the United States. We aimed to characterize race- and sex-based disparities in receipt of therapy and overall survival (OS) of SCCA using the SEER database. Methods: Cases of locoregional SCCA (T2-T4 any N M0) diagnosed between 2000 and 2012 in the SEER database were included. Demographics, tumor characteristics, type of therapy, and outcomes were extracted. Univariable and multivariable Cox proportional hazard models were constructed to test factors associated with OS. Data were reported as hazard ratios (HRs) and 95\% Cls. Results: A total of 7,882 cases of locoregional SCCA were identified, with a median age of 58 years, $61.2 \%$ of whom were women, and $86.3 \%$ were white. Most patients $(82.3 \%)$ received radiation therapy (RT), with the lowest rate in black men (76.7\%) and the highest in white women (86.1\%). The median OS was 135 months; OS was lower in elderly patients (age $\geq 65$ years; 68 months), men (108 months), blacks (109 months), and those who did not receive RT (121 months). In multivariable analysis, age (HR, 1.19; 95\% Cl, 1.17-1.21 per 5 years increase), sex (HR, $1.59 ; 95 \% \mathrm{Cl}$, 1.47-1.73, men vs women), race ( $\mathrm{HR}, 1.51 ; 95 \% \mathrm{Cl}, 1.34-1.71$, black vs white), and $\mathrm{RT}(\mathrm{HR}, 0.90 ; 95 \% \mathrm{Cl}, 0.82-0.99)$ were independently associated with OS $(P<.05)$. Conclusions: Significant race- and sex-based disparities exist in survival of patients with locoregional SCCA. Further investigation into the causes of these disparities and methods for elimination are warranted.
\end{abstract}

J Natl Compr Canc Netw 2017;15(8):998-1004 doi:10.6004/jnccn.2017.0135

\section{Background}

The NCI estimated that 8,080 new diagnoses of anal cancer and 1,080 deaths from the disease occurred in the United States in 2016. ${ }^{1}$ It remains one of few cancers in the United States with an increasing incidence over the past 3 decades $^{2-4}$ : from 0.8 per 100,000 persons in 1975 to 1.9 per 100,000 persons in 2013 , with the most rapid increase seen in black men. ${ }^{5}$

Squamous cell carcinoma of the anus (SCCA) is the most common histologic subtype of anal cancer, accounting for approximately $74 \%$ to $85 \%$ of cases. ${ }^{4,6}$ SCCA is strongly associated with human papilloma virus (HPV) and HIV infection. ${ }^{7}$ Therapy for locoregional

From the aDepartment of Internal Medicine, ${ }^{\text {} H}$ Harold Simmons Cancer Center, 'Department of Radiation Oncology, and dDepartment of Internal Medicine, Division of Hematology/Medical Oncology, The University of Texas Southwestern Medical Center, Dallas, Texas.

Submitted December 1, 2016; accepted for publication April 3, 2017.

Dr. Meyer has disclosed that he has received research support from

Peregrine Pharmaceuticals and DFIN, Inc. The remaining authors have

disclosed that they have no financial interests, arrangements, affiliations,

or commercial interests with the manufacturers of any products discussed
SCCA has largely remained unchanged over the past 2 decades, with combination chemotherapy and radiation therapy (RT) considered first-line therapy, and salvage surgery used for resistant or recurrent disease. ${ }^{8}$ Race and sex disparities related to access to care and outcomes have been studied for several malignancies, including pancreatic, breast, and lung cancers. ${ }^{9-11}$ Characterizing disparities can trigger investigations into the role of environmental risk factors, socioeconomic variables, and genetic predisposition across race and sex groups. ${ }^{12-15}$ However, studies on disparities of SCCA are limited.

Because SCCA has an increasing incidence with a historic predisposition to underserved and at-risk

in this article or their competitors.

Author contributions: Conception, design, analysis, and interpretation of data: Arora, Gupta, Zhu, Christie, Beg. Drafting, revision, and final approval of manuscript: Arora, Gupta, Zhu, Christie, Khan, Meyer, Beg. Correspondence: Muhammad S. Beg, MD, Division of Hematology/ Oncology, Department of Internal Medicine, UT Southwestern Medical Center, 5323 Harry Hines Boulevard, Dallas, TX 75390-8852.

E-mail: Muhammad.Beg@UTSouthwestern.edu 
populations, we aimed to study trends in race- and sex-based disparities in therapy for and outcomes of SCCA using the SEER database.

\section{Methods}

The NCI's SEER program contracts with populationbased cancer registries to provide data on all cancer cases and their tumor and epidemiologic characteristics. SEER*Stat was used for all data extraction, incidence, and survival rates. Individuals diagnosed with anal carcinoma (primary site C21.0 - C21.2) from 2000 through 2012 were included, and only those with locoregional disease, defined as T2-T4 any $\mathrm{N} \mathrm{MO}$ and confirmed squamous histology (ICDO histology codes 8010 and 8051-8081). Cases with nonsquamous cell histology, carcinoma in situ, and diagnosis by autopsy data/death certificate only were excluded. Age-standardized incidence rates per 100,000 for 2000 through 2012 were generated via SEER's Rate Session for white men, white women, black men, and black women. The trend of change in incidence rate between groups was compared by testing the interaction between time and group in the linear regression model. This study was considered exempt by the Institutional Review Board in accordance with the NIH Office for Human Research Protections (45 CFR 46.101(b)(4)).

Patient characteristics were described by age, sex, race, year of diagnosis, and receipt of radiation and surgery. Summary statistics for patient characteristics were reported using median and interquartile range for continuous variables, and using counts and percentages for discrete variables. The primary end point was overall survival (OS), which was defined as time (in months) from date of SCCA diagnosis until death from all causes as identified in SEER files. OS was estimated using the Kaplan-Meier survival method. Univariable and multivariable Cox regression analyses were used to assess the association between OS and patient characteristics. Hazard ratios (HRs) and 95\% CIs were reported. A secondary analysis to study predictors of receipt of RT was performed. Univariable and multivariable logistic regression analysis were used to identify the predictors for RT receipt. Odds ratios and 95\% CIs were reported, and the interaction effect between age and sex on the likelihood of receiving $R T$ was explored. Two-sided $P$ values were reported, and $P<.05$ was considered statistically sig- nificant. All analyses were conducted using SAS 9.4 (SAS Institute Inc., Cary, NC).

\section{Results}

There were 19,511 cases of anal cancer identified in SEER, of which 7,882 cases met inclusion criteria (Figure 1). Median age at diagnosis was 58 years, $61.2 \%$ were women, and $86.3 \%$ were white. Baseline patient characteristics are summarized in Table 1.

The incidence rate had the highest rate of increase for white women and black men $(0.06 / 100,000$ cases annually), whereas rates for black women and white men increased by 0.04 and $0.02 / 100,000$ cases annually, respectively. The overall test for difference in trend among the 4 groups had a $P$ value of 0.0099 .

Black and male patients were younger and had lower proportion of grade 3/4 disease, compared with white and female patients, respectively. On stratification of patients by race and sex, black patients (78.5\%) and male patients $(77.5 \%)$ had a lower rate

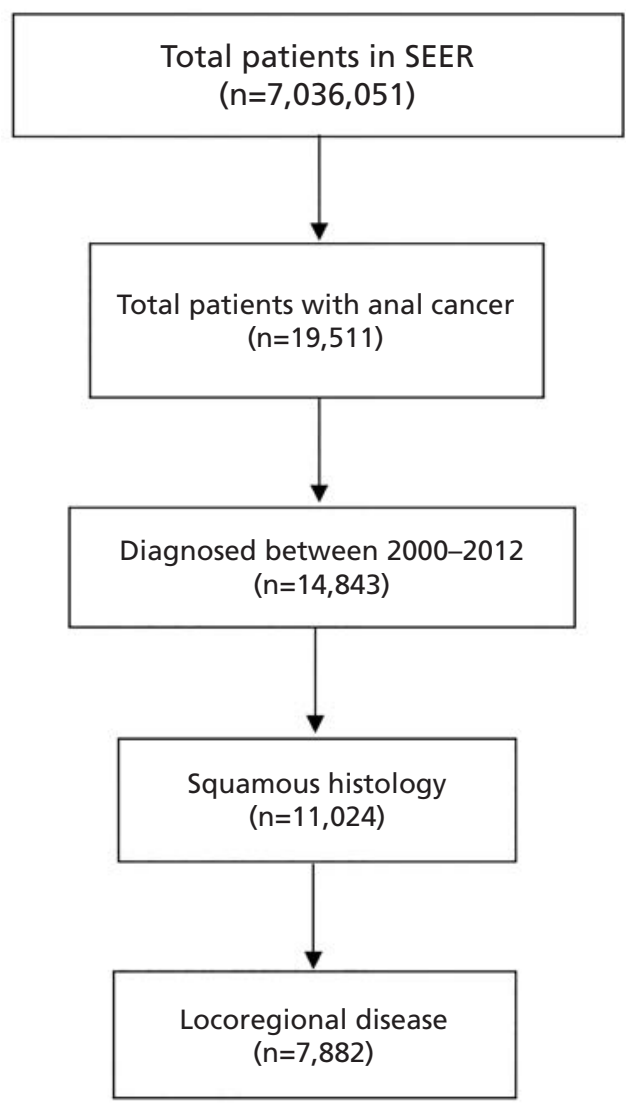

Figure 1. Flow diagram of the study. 
Arora et al

\begin{tabular}{|c|c|}
\hline & n (\%) \\
\hline \multicolumn{2}{|l|}{ Sex } \\
\hline Male & $3,057(38.8)$ \\
\hline Female & $4,825(61.2)$ \\
\hline \multicolumn{2}{|l|}{ Age at diagnosis, y } \\
\hline $18-49$ & $1,943(24.7)$ \\
\hline $50-64$ & $3,281(41.6)$ \\
\hline$\geq 65$ & $2,658(33.7)$ \\
\hline Age at diagnosis, y (median, IQR) & $58(50-69)$ \\
\hline \multicolumn{2}{|l|}{ Race } \\
\hline White & $6,805(86.3)$ \\
\hline Black & $859(10.9)$ \\
\hline Other & $180(2.3)$ \\
\hline Unknown & $38(0.5)$ \\
\hline \multicolumn{2}{|l|}{ Period of diagnosis } \\
\hline 2000-2003 & $2,157(27.4)$ \\
\hline $2004-2006$ & $1,464(18.6)$ \\
\hline 2007-2009 & $1,896(24.1)$ \\
\hline 2010-2012 & $2,365(30.0)$ \\
\hline \multicolumn{2}{|l|}{ Tumor grade at diagnosis } \\
\hline Grade $1 / 2$ & $3,938(66.2)$ \\
\hline Grade $3 / 4$ & $2,011(33.8)$ \\
\hline \multicolumn{2}{|l|}{ Surgery } \\
\hline Received & $347(4.4)$ \\
\hline Did not receive & $7,464(95.6)$ \\
\hline \multicolumn{2}{|l|}{ Radiation } \\
\hline Received & $6,408(82.3)$ \\
\hline Did not receive & $1,377(17.7)$ \\
\hline
\end{tabular}

Abbreviation: IQR, interquartile range.

of RT use than white patients $(82.9 \%)$ and female patients $(85.4 \%)$, respectively. Supplemental eTable 1 summarizes the characteristics of patients stratified by race and sex (available with this article at INCCN.org).

Median OS of the cohort was 135 months. Kaplan-Meier curves for survival of patients with SCCA comparing white women (ref), white men (HR, 1.35; 95\% CI, 1.24-1.47), black women (HR, 1.29; 95\% CI, 1.09-1.53), and black men (HR, 1.62; 95\% CI, 1.38-1.91) are presented in Figure 2 (log rank test $P<.0001)$. Median OS for white women was 148 months, followed by black women (146 months), white men (111 months), and black men (82 months).

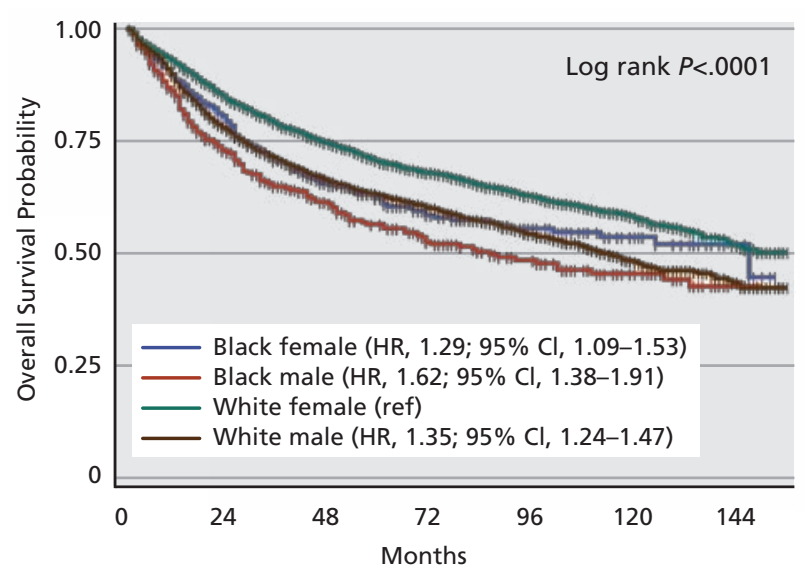

Figure 2. Kaplan-Meier curve demonstrating overall survival of squamous cell carcinoma of the anus in SEER from 2000-2012 among the 4 racial/sex groups.

Abbreviation: HR, hazard ratio.

On univariable analysis, younger age, female sex, white race, receipt of RT, and nonreceipt of surgery were associated with improved survival, whereas period of diagnosis and grade of tumor were not (Table 2). On multivariable analysis, increasing age (HR, 1.19; $95 \%$ CI, $1.17-1.21$ per 5-year increase), sex (HR, 1.59; 95\% CI, 1.47-1.73, men vs women), race (HR, 1.51; 95\% CI, 1.34-1.71, black vs white), and receipt of RT (HR, 0.90; 95\% CI, 0.82-0.99), were all independently associated with OS (all $\mathrm{P}<.05$; Table 3 ). The multivariable logistic regression analysis suggested that there was no interaction between age and sex in the likelihood of receiving RT $(P=.358)$. Table 4 includes the results of univariable logistic regression analysis and multivariable logistic regression analyses with and without the interaction term.

Additional analysis was performed to understand factors predicting receipt of RT (Table 4). After multivariable adjustment, advanced age (age $\geq 65$ years vs 18-49 years), male sex (vs female), and grade $1 / 2$ disease (vs grade 3/4) were independently associated with lower rates of RT receipt. Black race was associated with a lower rate of RT receipt on univariable analysis, which did not persist after multivariable adjustment.

\section{Discussion}

Using a nationally representative cohort, we demonstrate significant race- and sex-based disparities in the treatment and outcomes of patients with locoregional SCCA. Black men had the lowest median 
Disparities in Anal Cancer Survival

\begin{tabular}{|c|c|c|c|c|}
\hline & \multirow{2}{*}{$\begin{array}{c}\text { 5-Year Survival, } \\
\%(95 \% \mathrm{Cl})\end{array}$} & \multirow{2}{*}{$\begin{array}{c}\text { Median OS, } \\
\text { mo }\end{array}$} & \multicolumn{2}{|c|}{ Univariable Analysis } \\
\hline & & & HR $(95 \% \mathrm{Cl})$ & $P$ Value $^{\mathrm{a}}$ \\
\hline Overall & $66.0(64.8,67.2)$ & 135 & NA & \\
\hline \multicolumn{5}{|l|}{ Sex } \\
\hline Female & $69.0(67.4,70.5)$ & 148 & ref & \\
\hline Male & $61.4(59.4,63.3)$ & 108 & $1.36(1.26,1.47)$ & $<.0001$ \\
\hline \multicolumn{5}{|l|}{ Age at diagnosis } \\
\hline Per 5 years increase & NA & NA & $1.16(1.15,1.18)$ & $<.0001$ \\
\hline \multicolumn{5}{|l|}{ Race } \\
\hline White & $66.9(65.5,68.1)$ & 137 & ref & \\
\hline Black & $57.9(53.9,61.7)$ & 109 & $1.28(1.14,1.44)$ & $<.0001$ \\
\hline Other & $68.5(59.6,75.8)$ & 140 & $0.96(0.73,1.25)$ & .75 \\
\hline \multicolumn{5}{|l|}{ Period of diagnosis } \\
\hline $2000-2003$ & $66.4(64.4,68.4)$ & 138 & ref & \\
\hline 2004-2006 & $66.2(63.7,68.6)$ & NR & $1.02(0.92,1.14)$ & .66 \\
\hline 2007-2009 & $63.9(61.4,66.3)$ & NR & $1.08(0.97,1.20)$ & .13 \\
\hline $2010-2012$ & NA & NR & $0.92(0.80,1.05)$ & .22 \\
\hline \multicolumn{5}{|c|}{ Tumor grade at diagnosis } \\
\hline Grade $1 / 2$ & $65.8(64.1,67.5)$ & 137 & ref & \\
\hline Grade $3 / 4$ & $62.8(60.3,65.2)$ & 122 & $1.09(0.99,1.20)$ & .06 \\
\hline \multicolumn{5}{|l|}{ Surgery } \\
\hline Did not receive & $67.1(65.9,68.4)$ & 141 & ref & \\
\hline Received & $43.9(37.8,49.8)$ & 43 & $1.91(1.64,2.22)$ & $<.0001$ \\
\hline \multicolumn{5}{|l|}{ Radiation } \\
\hline Did not receive & $63.6(60.7,66.4)$ & 121 & ref & \\
\hline Received & $66.7(65.3,68.0)$ & 141 & $0.85(0.77,0.93)$ & .0008 \\
\hline
\end{tabular}

Abbreviations: HR, hazard ratio; NA, not applicable; NR, not reported; OS, overall survival.

a $P$ value based on Cox regression analysis.

survival. After adjusting for tumor and treatment variables, race and sex were independent predictors of survival, suggesting inherent differences in tumor biology.

Standard treatment for locoregional SCCA comprises a combination of chemotherapy and RT, with salvage surgery reserved for those with residual or recurrent disease. ${ }^{16}$ Race- and sex-based disparities in outcomes have been reported in the context of several other cancers. ${ }^{17-21}$ Understanding healthcare disparities in SCCA is crucial because it largely affects at-risk and vulnerable populations, including ethnic minorities and individuals with HIV. Data from other cancer types demonstrate that nonwhite patients experience delays in diagnosis and treatment, and are less likely to receive guideline-adherent treatment. ${ }^{22-24}$ These disparities are a result of a complex interplay of social, economic, biologic,

\begin{tabular}{|c|c|c|}
\hline & \multicolumn{2}{|c|}{ Multivariable Analysis } \\
\hline & HR $(95 \% \mathrm{Cl})$ & $P$ Value ${ }^{a}$ \\
\hline \multicolumn{3}{|l|}{ Sex } \\
\hline Women & ref & \\
\hline Men & $1.59(1.47,1.73)$ & $<.0001$ \\
\hline \multicolumn{3}{|l|}{ Age at diagnosis } \\
\hline Per 5 years increase & $1.19(1.17,1.21)$ & $<.0001$ \\
\hline \multicolumn{3}{|l|}{ Race } \\
\hline White & ref & \\
\hline Black & $1.51(1.34,1.71)$ & $<.0001$ \\
\hline Other & $1.01(0.77,1.32)$ & .95 \\
\hline \multicolumn{3}{|l|}{ Radiation } \\
\hline Did not receive & ref & \\
\hline Received & $0.90(0.82,0.99)$ & .04 \\
\hline
\end{tabular}

Abbreviation: HR, hazard ratio.

a $P$ value based on Cox regression analysis. 
Arora et al

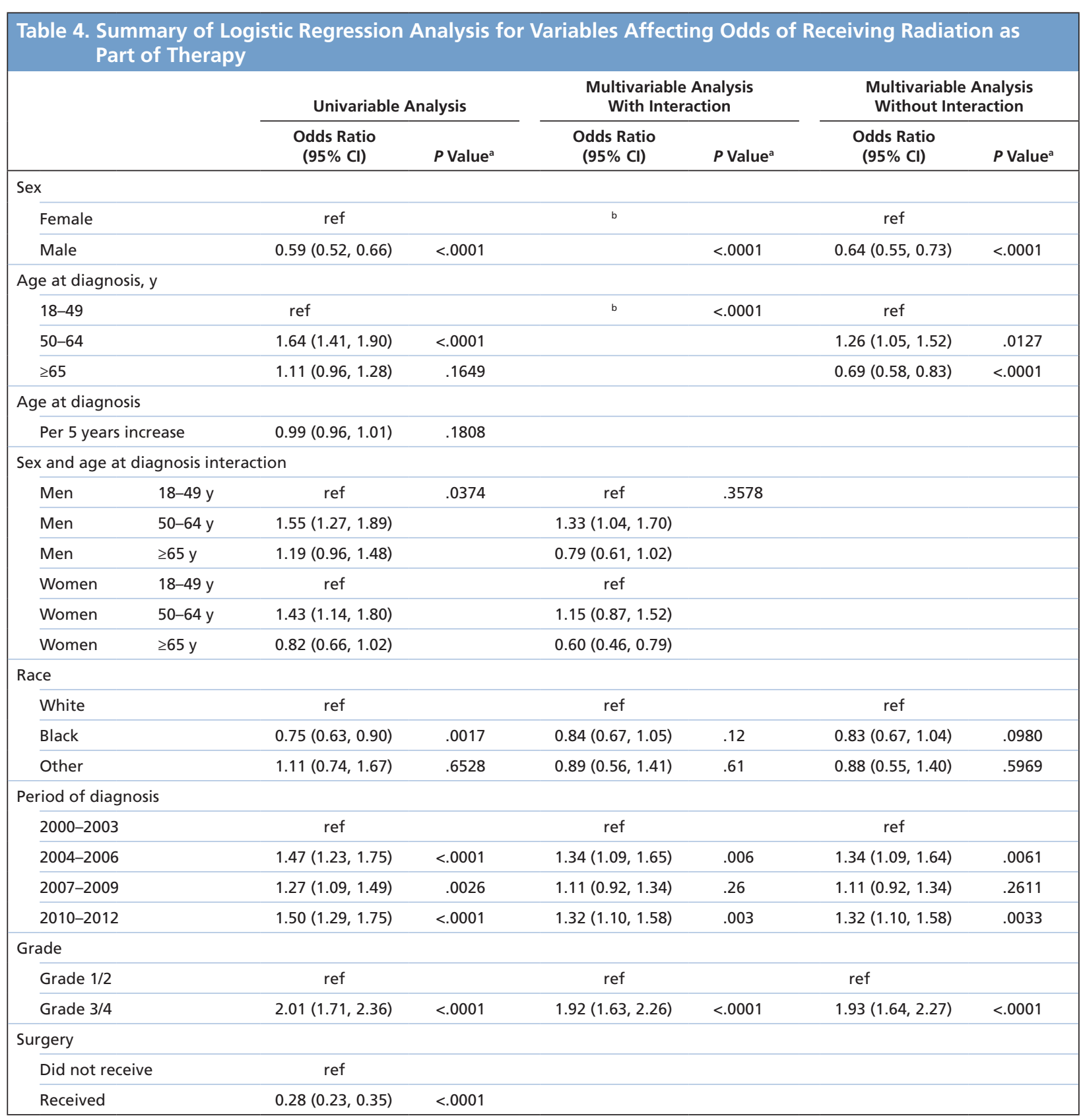

a $P$ value based on Logistic regression analysis.

bSee interaction term.

and cultural factors; these in turn influence disease prevention, time of detection, diagnosis, treatment, and posttreatment quality of life, which can manifest as an observable difference in survival and mortality rates. ${ }^{25}$ Patients with low socioeconomic status are more likely to lack health insurance, have lower health literacy, have poor geographic access to healthcare, and harbor higher rates of distrust of the healthcare system. ${ }^{26-28}$ These findings are highly relevant for SCCA, wherein patients presenting to a public safety net hospital with a higher rate of Hispanic and black patients had higher rates of delayed or interrupted RT and poorer OS compared with those presenting to a private hospital. ${ }^{29}$

HIV and HPV status may represent indirect influences on the observed disparities of SCCA outcomes. HIV-positive individuals with SCCA are more likely to be younger, male, and black. ${ }^{30} \mathrm{~A}$ 
recent study identified 1997 as the time point when the rates of SCCA shifted most dramatically. ${ }^{6} \mathrm{Be}$ cause the risk of SCCA is highest in patients with HIV after $\geq 15$ years of infection, ${ }^{31}$ this has been correlated with the time course of the HIV epidemic, which began in the early 1980s. The increasing rate of anal cancer incidence in the United States has been correlated to the HIV epidemic in men, but is reported to be independent of HIV infection in women. ${ }^{32}$ Compared with HIV-negative men who have sex with men, those who are HIV-positive have a higher risk of harboring high-risk HPV types 16 and $18,{ }^{33}$ which are known to be associated with anal dysplasia and SCCA. ${ }^{34}$ Studies evaluating prognosis of HIV based on sex have observed that male patients with HIV have faster disease progression and earlier mortality than female patients..$^{35,36}$

Disparities in outcomes between men and women have been observed in a number of solid malignancies, including colorectal, ${ }^{37}$ hepatocellular, ${ }^{38}$ and lung cancers. ${ }^{39}$ In metastatic colorectal cancer, premenopausal women have been observed to have a survival advantage over similarly aged men, which is lost after menopause. ${ }^{37}$ Women have been reported to also have a survival advantage in oropharyngeal squamous cell cancer, which, like SCCA, is a HPVassociated malignancy..$^{40}$ In anal cancer, our findings suggest that female patients are more likely to receive radiation as part of therapy, and it has been reported that women are more likely to adhere to therapy as well. ${ }^{41}$ The exact mechanism of the observed survival advantage in women remains unknown, although it is likely a result of an interaction between biological and behavioral differences, comorbidities such as HIV status, healthcare utilization, and compliance with therapy. Further investigation into causes of this disparity could shed light on means to improve outcomes in male patients.

Our findings that black men have poor survival after adjusting for tumor and treatment characteristics suggest an impact not only of potential delays in treatment, but also underlying tumor biology. With the advent of highly active antiretroviral therapy (HAART), HIV-positive patients with SCCA have had management strategies and survival rates comparable to those of HIV-negative patients. ${ }^{42-44}$ Lower rates of HAART adherence in black patients may further contribute to poorer cancer outcomes. ${ }^{45,46} \mathrm{We}$ have identified treatment disparities as one of the factors likely influencing the differences in outcome among patients with SCCA.

Our study has notable limitations that are inherent to a large database analysis. Impact of treatment delays, quality of RT, administration of concurrent chemotherapy, and treatment toxicities could not be assessed. We were unable to stratify our analysis based on HIV and HPV status, and molecular characterization of cancers was not available.

\section{Conclusions}

Race- and sex-based disparities reflect the fact that SCCA diagnosis and management is complex and requires coordination among multiple specialities and healthcare teams. Recognizing multiple opportunities to optimize anal cancer care along the cancer care continuum is essential to help improve outcomes and reduce disparities. ${ }^{47,48}$ Successful screening strategies to identify anal cancer in at-risk populations can help close this gap. ${ }^{49}$ The effectiveness of these strategies is affected by factors at the patient, provider, and system levels. Patient education on the importance of self-management of comorbid conditions (HIV), lifestyle modification, and identifying and following up on nonmalignant anogenital warts is necessary. Primary care physicians can identify high-risk individuals to enable targeted screening efforts. Healthcare systems can engage patient support groups and use electronic medical record data fields to offer practice alerts and for screening and counseling.

\section{References}

1. Siegel RL, Miller KD, Jemal A. Cancer statistics, 2016. CA Cancer J Clin 2016;66:7-30.

2. Johnson LG, Madeleine MM, Newcomer LM, et al. Anal cancer incidence and survival: the Surveillance, Epidemiology, and End Results experience, 1973-2000. Cancer 2004;101:281-288.

3. Wilkinson JR, Morris EJ, Downing A, et al. The rising incidence of anal cancer in England 1990-2010: a population-based study. Colorectal Dis 2014;16:O234-239.

4. Klas JV, Rothenberger DA, Wong WD, Madoff RD. Malignant tumors of the anal canal: the spectrum of disease, treatment, and outcomes. Cancer 1999;85:1686-1693.

5. Gomez-Puerta JA, Cervera R. Diagnosis and classification of the antiphospholipid syndrome. J Autoimmun 2014;48-49:20-25

6. Nelson RA, Levine AM, Bernstein L, et al. Changing patterns of anal canal carcinoma in the United States. J Clin Oncol 2013;31:1569-1575.

7. Franceschi S, De Vuyst H. Human papillomavirus vaccines and anal carcinoma. Curr Opin HIV AIDS 2009;4:57-63. 
8. Shridhar R, Shibata D, Chan E, Thomas CR. Anal cancer: current standards in care and recent changes in practice. CA Cancer J Clin 2015;65:139-162.

9. Khawja SN, Mohammed S, Silberfein EJ, et al. Pancreatic cancer disparities in African Americans. Pancreas 2015;44:522-527.

10. Newman LA. Disparities in breast cancer and african ancestry: a global perspective. Breast J 2015;21:133-139.

11. Berger M, Lund MJ, Brawley OW. Racial disparities in lung cancer. Curr Probl Cancer 2007;31:202-210.

12. Daly B, Olopade OI. A perfect storm: how tumor biology, genomics, and health care delivery patterns collide to create a racial survival disparity in breast cancer and proposed interventions for change. CA Cancer J Clin 2015;65:221-238

13. Carethers JM. Screening for colorectal cancer in African Americans: determinants and rationale for an earlier age to commence screening. Dig Dis Sci 2015;60:711-721.

14. O'Keefe EB, Meltzer JP, Bethea TN. Health disparities and cancer: racial disparities in cancer mortality in the United States, 2000-2010. Front Public Health 2015;3:51.

15. Shavers VL, Brown ML. Racial and ethnic disparities in the receipt of cancer treatment. J Natl Cancer Inst 2002;94:334-357.

16. Alamri Y, Buchwald P, Dixon L, et al. Salvage surgery in patients with recurrent or residual squamous cell carcinoma of the anus. Eur J Surg Oncol 2016;42:1687-1692.

17. Benjamins MR, Hunt BR, Raleigh SM, et al. Racial disparities in prostate cancer mortality in the 50 largest US cities. Cancer Epidemiol 2016;44:125-131.

18. Akinyemiju T, Moore JX, Ojesina AI, et al. Racial disparities in individual breast cancer outcomes by hormone-receptor subtype, area-level socioeconomic status and healthcare resources. Breast Cancer Res Treat 2016;157:575-586

19. Williams R, White $P$, Nieto J, et al. Colorectal cancer in African Americans: an update. Clin Transl Gastroenterol 2016;7:e185.

20. Berger MD, Yang D, Sunakawa $Y$, et al. Impact of sex, age, and ethnicity/ race on the survival of patients with rectal cancer in the United States from 1988 to 2012. Oncotarget 2016;7:53668-53678

21. Kim HW, Kim JH, Lim BJ, et al. Sex disparity in gastric cancer: female sex is a poor prognostic factor for advanced gastric cancer. Ann Surg Oncol 2016;23:4344-4351.

22. Bristow RE, Chang J, Ziogas A, et al. Spatial analysis of adherence to treatment guidelines for advanced-stage ovarian cancer and the impact of race and socioeconomic status. Gynecol Oncol 2014;134:60-67.

23. Chang EH, Lutfi W, Feinglass J, et al. National trends in the surgical treatment of non-advanced medullary thyroid cancer (MTC): an evaluation of adherence with the 2009 American Thyroid Association guidelines. World J Surg 2016;40:2930-2940.

24. Dell'Oglio P, Abou-Haidar H, Leyh-Bannurah SR, et al. Assessment of the rate of adherence to international guidelines for androgen deprivation therapy with external-beam radiation therapy: a population-based study. Eur Urol 2016;70:429-435

25. Ward E, Jemal A, Cokkinides V, et al. Cancer disparities by race/ethnicity and socioeconomic status. CA Cancer J Clin 2004;54:78-93.

26. Armstrong K, McMurphy S, Dean LT, et al. Differences in the patterns of health care system distrust between blacks and whites. J Gen Intern Med 2008;23:827-833.

27. LaVeist TA, Nickerson KJ, Bowie JV. Attitudes about racism, medical mistrust, and satisfaction with care among African American and white cardiac patients. Med Care Res Rev 2000;57(Suppl 1):146-161.

28. Lin JJ, Mhango G, Wall MM, et al. Cultural factors associated with racial disparities in lung cancer care. Ann Am Thorac Soc 2014;11:489-495.

29. Bitterman DS, Grew D, Gu P, et al. Comparison of anal cancer outcomes in public and private hospital patients treated at a single radiation oncology center. J Gastrointest Oncol 2015;6:524-533.
30. Chiao EY, Giordano TP, Richardson P, El-Serag HB. Human immunodeficiency virus-associated squamous cell cancer of the anus: epidemiology and outcomes in the highly active antiretroviral therapy era. J Clin Oncol 2008;26:474-479.

31. Crum-Cianflone NF, Hullsiek KH, Marconi VC, et al. Anal cancers among HIV-infected persons: HAART is not slowing rising incidence. AIDS 2010;24:535-543.

32. Shiels MS, Pfeiffer RM, Chaturvedi AK, et al. Impact of the HIV epidemic on the incidence rates of anal cancer in the United States. J Natl Cancer Inst 2012;104:1591-1598.

33. Alberts CJ, van Rooijen MS, Prins M, et al. HIV is an important risk factor for human papillomavirus types 16 and 18 seropositivity among sexually active men who have sex with men. Sex Transm Dis 2015;42:129-134.

34. Assi R, Reddy V, Einarsdottir H, Longo WE. Anorectal human papillomavirus: current concepts. Yale J Biol Med 2014;87:537-547.

35. Abioye AI, Soipe AI, Salako AA, et al. Are there differences in disease progression and mortality among male and female HIV patients on antiretroviral therapy? A meta-analysis of observational cohorts. AIDS Care 2015;27:1468-1486.

36. Jarrin I, Geskus R, Bhaskaran K, et al. Gender differences in HIV progression to AIDS and death in industrialized countries: slower disease progression following HIV seroconversion in women. Am J Epidemiol 2008;168:532-540.

37. Hendifar A, Yang D, Lenz F, et al. Gender disparities in metastatic colorectal cancer survival. Clin Cancer Res 2009;15:6391-6397.

38. Yeh SH, Chen PJ. Gender disparity of hepatocellular carcinoma: the role of sex hormones. Oncology 2010;78(Suppl 1):172-179.

39. Nakamura $\mathrm{H}$, Ando $\mathrm{K}$, Shinmyo T, et al. Female gender is an independent prognostic factor in non-small-cell lung cancer: a meta-analysis. Ann Thorac Cardiovasc Surg 2011;17:469-480.

40. Fakhry C, Westra WH, Wang SJ, et al. The prognostic role of sex, race, and human papillomavirus in oropharyngeal and nonoropharyngeal head and neck squamous cell cancer. Cancer 2017;123:1566-1575.

41. Osazuwa-Peters N, Massa ST, Christopher KM, et al. Race and sex disparities in long-term survival of oral and oropharyngeal cancer in the United States. J Cancer Res Clin Oncol 2016;142:521-528.

42. Hleyhel M, Belot A, Bouvier AM, et al. Trends in survival after cancer diagnosis among HIV-infected individuals between 1992 and 2009. Result from the FHDH-ANRS CO4 cohort. Int J Cancer 2015;137:2443-2453.

43. Hammad N, Heilbrun LK, Gupta S, et al. Squamous cell cancer of the anal canal in HIV-infected patients receiving highly active antiretroviral therapy: a single institution experience. Am J Clin Oncol 2011;34:135139.

44. Marin-Muller C, Li M, Chen C, Yao Q. Current understanding and potential immunotherapy for HIV-associated squamous cell carcinoma of the anus (SCCA). World J Surg 2009;33:653-660.

45. Simoni JM, Huh D, Wilson IB, et al. Racial/Ethnic disparities in ART adherence in the United States: findings from the MACH14 study. J Acquir Immune Defic Syndr 2012;60:466-472.

46. Kong MC, Nahata MC, Lacombe VA, et al. Association between race, depression, and antiretroviral therapy adherence in a low-income population with HIV infection. J Gen Intern Med 2012;27:1159-1164.

47. Leyden WA, Manos MM, Geiger AM, et al. Cervical cancer in women with comprehensive health care access: attributable factors in the screening process. J Natl Cancer Inst 2005;97:675-683.

48. Taplin SH, Ichikawa L, Yood MU, et al. Reason for late-stage breast cancer: absence of screening or detection, or breakdown in follow-up? J Natl Cancer Inst 2004;96:1518-1527.

49. Leeds IL, Fang SH. Anal cancer and intraepithelial neoplasia screening: a review. World J Gastrointest Surg 2016;8:41-51. 